\title{
PREVENCIÓN DE LA MALARIA MEDIANTE ESTRATEGIAS MEDIOAMBIENTALES $Y$ TÉCNICAS TRADICIONALES APLICADAS A LA ARQUITECTURA*
}

Alejandro Ordoñez Ortiz***

Universidad Santo Tomás, Colombia

Localización, Camerún y comunidad de Minkoaméyos donde se desarrolló la propuesta. Suministrada por el autor a partir de la información suministrada dentro de las bases del concurso internacional Building Malaria Prevention por la organización Archive Global Architecture for Health.
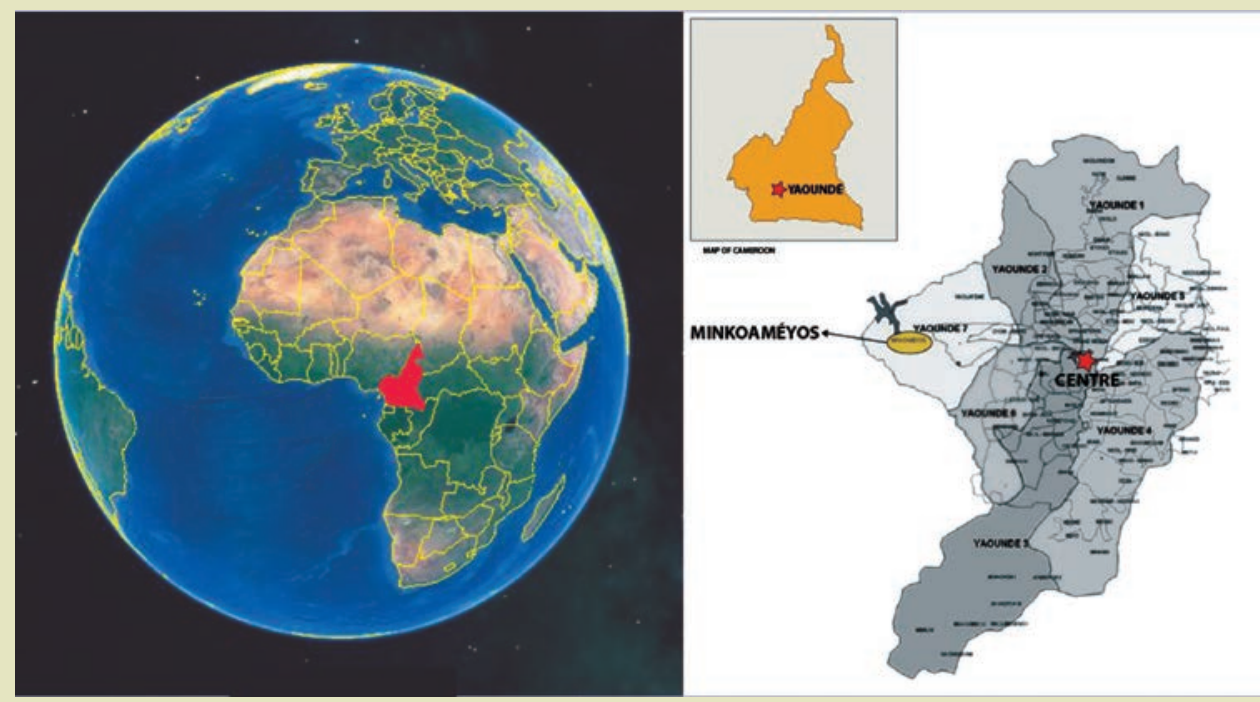

"Este artículo se deriva del trabajo de equipo realizado por Alejandro Ordóñez Ortiz, arquitecto perteneciente a Citu Experiencia Local, Laboratorio de Proyectos Urbanos, en asocio con los arquitectos Erika Gómez y Gustavo Bautista de Contrapunto Taller de Arquitectura, quienes participaron en el Concurso Internacional "Building Malaria Prevention" ("Construyendo la prevención de la malaria"), convocado en 2012 por la organización Archive Global - Architecture for Health; el fallo del jurado, emitido el 3 de octubre de 2012 , consideró a esta propuesta como la mejor, otorgándole el primer lugar."

** Arquitecto, investigador urbano y docente.

alejandrordonez@gmail.com

\section{RESUMEN}

El presente escrito indaga sobre la naturaleza del riesgo, su relación con la arquitectura y la salud bajo los presupuestos de la Organización Mundial de la Salud, OMS y la Comisión Económica para América Latina y el Caribe, CEPAL. También plantea estrategias de superación para una problemática específica: la Malaria, enfermedad responsable del $50 \%$ de muertes en menores de 5 años en Camerún. Con la anuencia de la organización Archive Global Architecture for Health, y bajo los parámetros del concurso internacional de arquitectura y salud Bulding Malaria Prevention, se enuncia un diseño de vivienda capaz de mitigar hasta en un $90 \%$ el riesgo de contagio de Malaria, que será definitivo para la superación de las penosas condiciones habitacionales y de salud presentes en 24 familias en Yaoundé. La mitigación del riesgo se convierte, entonces, en la prueba fehaciente sobre la pertinencia de la arquitectura como disciplina fundamental para la humanidad.

\section{PALABRAS CLAVE}

Riesgo, Mitigación, Malaria, África, Arquitectura, Salud, Concurso Internacional. 


\section{MALARIA PREVENTION THROUGH ENVIRONMENTAL STRATEGIES AND TRADITIONAL TECHNIQUES APPLIED TO ARCHITECTURE}

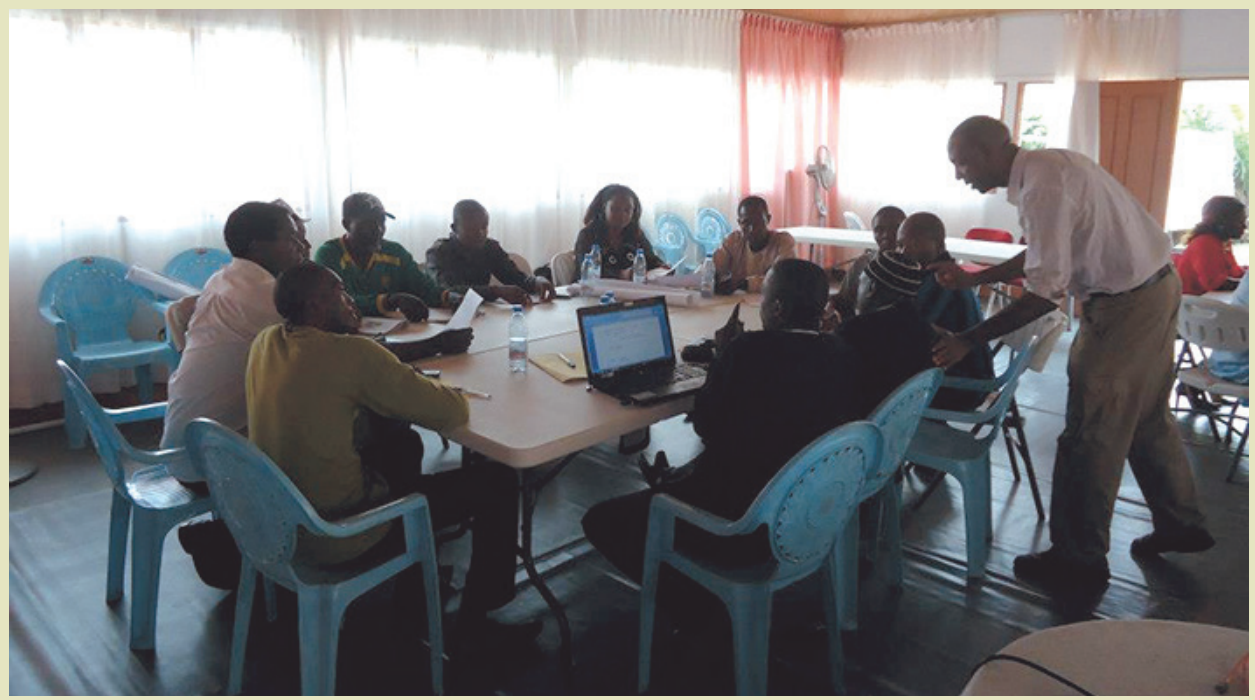

\begin{abstract}
This paper explores the nature of risk and its relation to architecture and health budgets under WHO and ECLAC. It also presents strategies for overcoming specific problems: Malaria, a disease responsible for $50 \%$ of deaths in children under 5 years in Cameroon. With the consent of the organization Archive Global Architecture for Health and the parameters of the international architectural competition Malaria Prevention and Building Health, sets out a housing design can mitigate up to $90 \%$ the risk of spread of Malaria , which will definitive overcoming the painful housing and health conditions present in 24 families in Yaoundé. Risk mitigation then becomes the proof of the relevance of architecture as a discipline essential to humanity.
\end{abstract}

\section{KEYWORDS}

Risk, Mitigation, Malaria, Africa, architecture, health, International Competition.
Socialización del proyecto junto con Archive Global en Camerún. Suministrada por el autor. 


\section{Con una naturaleza confortable el hombre jamás habría inventado la arquitectura.}

\section{Oscar Wilde}

El riesgo como concepto no es la catástrofe, sino su probabilidad de ocurrir; la probabilidad entraña entonces la vulnerabilidad de quien está en situación de riesgo. El concepto involucra así partes iguales de probabilidad y vulnerabilidad en aquellos seres y lugares sumidos en condiciones extremas.

Tanto para la OMS como para la CEPAL, el riesgo en salud y arquitectura son situaciones idénticas cuando en zonas deprimidas coexisten factores de peligro relacionados con amenazas naturales, biológicas, cambios climáticos, deficiencias de saneamiento básico, además de la falta de higiene relacionada con las características de las construcciones habitadas; entonces se asiste a un escenario donde la vulnerabilidad y la probabilidad son reales hasta el punto de poner en riesgo la vida humana. De esto se infiere necesariamente que el habitar implica riesgo.

A la luz de estas consideraciones plantearse una posición dentro del estudio arquitectónico que atienda a las necesidades de mitigación de riesgos y donde todavía el sentido de la arquitectura sea la protección de seres humanos resulta, por lo menos, imperativo. El pensamiento arquitectónico debe ir, entonces, más allá que su consolidación en el espacio, para ir incluso sobre la vida de las personas y sobre el concepto mismo de riesgo, si se lo considera desde una visión integral.

Un caso que puede aludirse es el de la arquitectura pensada para la prevención de enfermedades como riesgos. Por ejemplo, Le Corbusier en su memorable Carta de Atenas señala la necesidad de entender la relación del entorno arquitectónico y la salud: " $E l$ sol, que preside todo proceso de crecimiento, debería penetrar en el interior de cada vivienda para esparcir en ella sus rayos, sin los cuales la vida se marchita." La modernidad ha ligado sendos esfuerzos por mostrar las ventajas de la luz natural y la ventilación para la prevención de las enfermedades; desde la liberación de la planta lograda con el uso generalizado del concreto reforzado, se pasó al concepto de fachada libre y con él, a los amplios ventanales que garantizan la ventilación cruzada y la iluminación de los espacios. Así, la arquitectura ha sido capaz en las décadas precedentes de brindar soluciones que impacten en las problemáticas del cuerpo humano para mitigar el riesgo como en ninguna otra época de la humanidad.

A la luz de la anterior consideración la organización Archive Global Architecture for Health, que basa su accionar en la capacidad de la arquitectura para incidir positivamente en la salud de los habitantes, lanzó el concurso internacional Bulding Malaria Prevention, que buscaba premiar el mejor diseño de una vivienda capaz de mitigar el riesgo de contagio de Malaria en Camerún, país africano donde el $50 \%$ de muertes en menores de 5 años se debe a esta enfermedad, que ataca especialmente en zonas socio-económicamente vulnerables. En otras palabras, la arquitectura se aborda aquí como un instrumento para combatir la Malaria bajo los presupuestos de la misión de Archive Global que "se centra en el uso de un derecho fundamental - la vivienda - para entregar una necesidad básica - la salud.” 


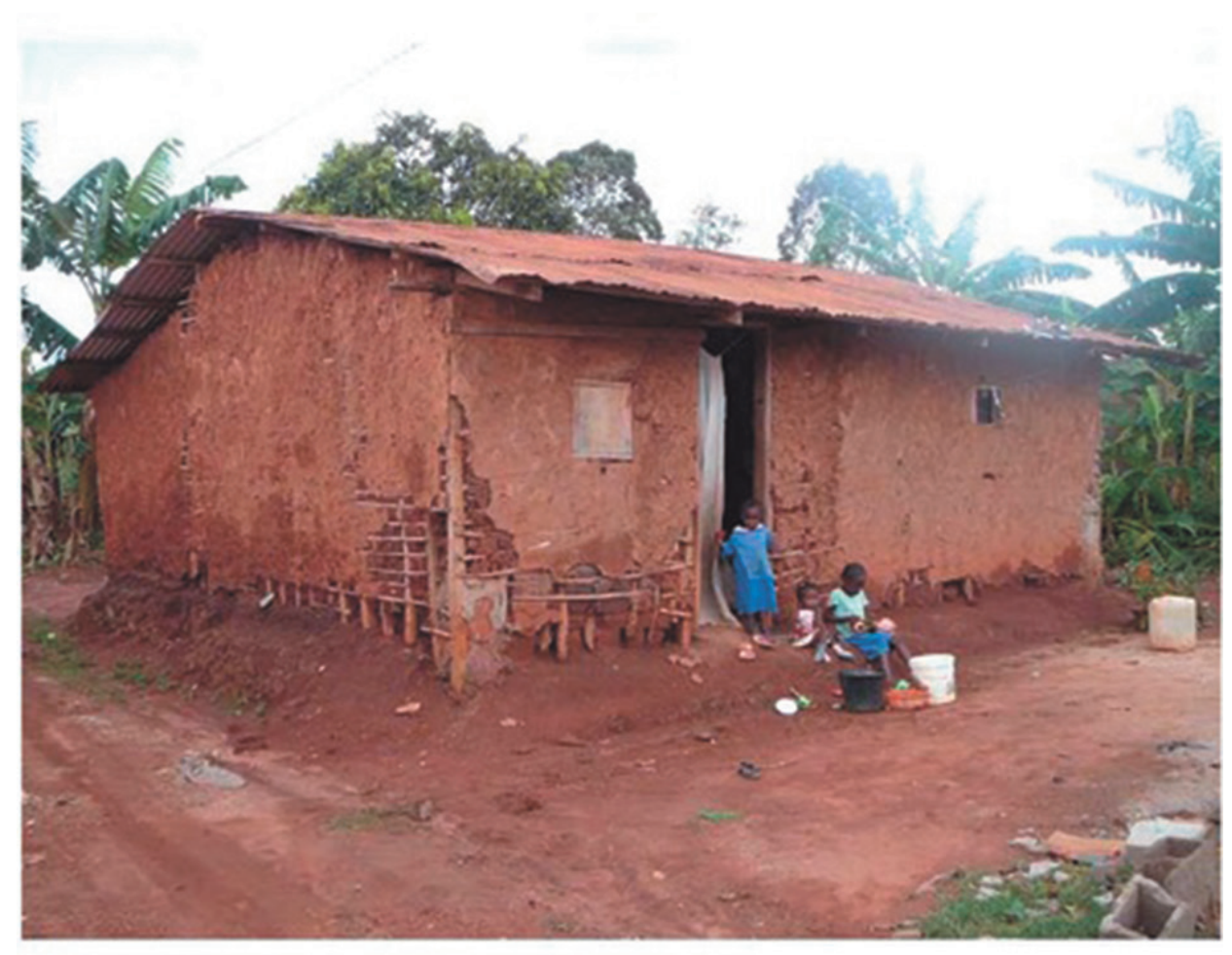

Figura I. Condiciones de vivienda y letrinas en Yaoundé, Camerún. Fuente: Información suministrada dentro de las bases del concurso internacional Building Malaria Prevention por la organización Archive Global Architecture for Health.
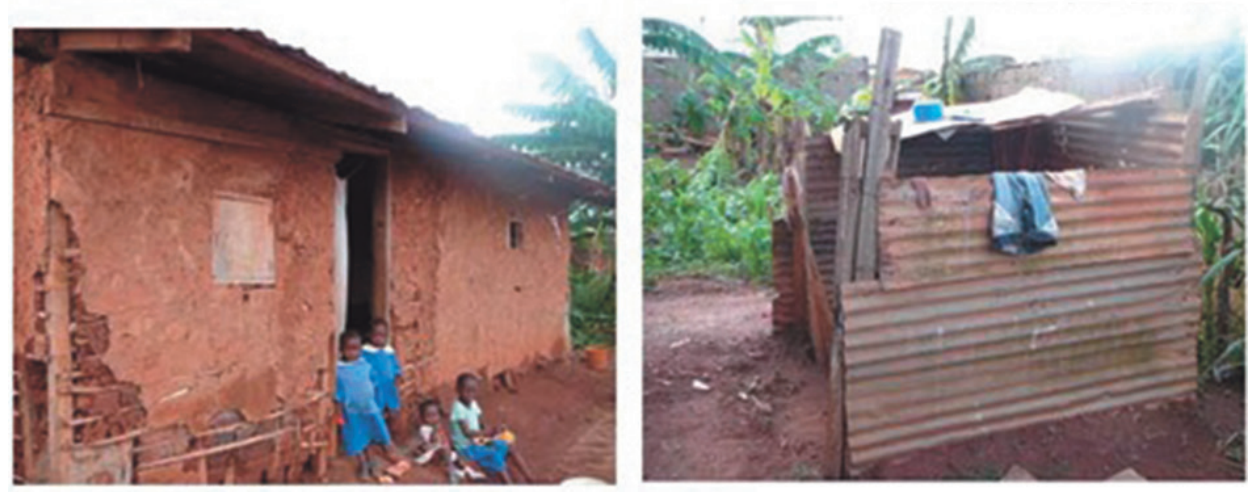

La Malaria es una enfermedad que coexiste con la pobreza extrema. Esta aseveración se hace evidente al contrastar las cifras de los casos de muerte por malaria y su localización; esto es, la muerte por la enfermedad se concentra en el continente más pobre del mundo: África, donde la tasa de mortalidad, y peor, de mortalidad infantil, tienen una relación directa con el contagio del Anopheles Gambiae', hasta llegar incluso al punto de producir más de 300.000 muertes infantiles en el 2010 . Archive Global vincula esta alta tasa de mortalidad y las condiciones reinantes al interior de una vivienda, como habitáculo destinado a la protección.

Ahora bien, ¿Cómo pensar entonces en una solución integral de vivienda que trascienda a su uso de hábitat, para incluir en ella la mitigación de riesgos como el desarraigo social, la ausencia de oportunidades, o incluso enfermedades contagiosas como la Malaria?

I Mosquitos Culícidos responsables de la mayoría de contagios de Malaria en el mundo. 
El arquitecto Alejandro Ordóñez Ortiz, en asocio con Contra Punto Taller de Arquitectura, formuló un diseño de vivienda capaz de mitigar, según estimaciones, hasta en un $80 \%$ la probabilidad de contagio en zonas de Camerún vulnerables a la Malaria. Esta propuesta, que conjuga en su diseño saberes tradicionales autóctonos propios de la cultura africana, la cohesión social y el diseño arquitectónico, se alzó con el primer puesto entre más de 450 propuestas presentadas a Archive Global en la convocatoria antes descrita.

Para entender el proceso, es necesario socavar sobre la naturaleza del contagio de la Malaria, descrita por la OMS a partir de vectores de riesgo: un mosquito, la noche, condiciones de insalubridad, ausencia de ventilación pero al mismo tiempo de repelencia: tales vectores disparan el riesgo de contagio por medio de la picadura del Anopheles Gambiae. Esto plantea de inmediato la necesidad de repeler al mosquito mediante una transformación del espacio habitado. Se hace necesario preguntar: ¿Cómo adelantar una transformación del espacio arquitectónico capaz de prevenir factores de riesgo, con la precariedad contextual que rodea a la situación africana?

En la formulación del proyecto, (ver Figura 2) los principios rectores que se trazaron como objetivos fueron tres: (I) Repeler al mosquito. (II) Impedir el acceso del mosquito a la vivienda. (III) Proteger a los habitantes al interior de la vivienda. ¿Cómo lograr esto sin perder de vista las condiciones de extrema pobreza persistentes en la zona?

Figura 2. Cuadro conceptual de principios y estrategias hacia la prevención de la Malaria en la vivienda propuesta. Fuente: Arquitecto Alejandro Ordóñez y Contrapunto Taller de Arquitectura. Suministrada por el autor.

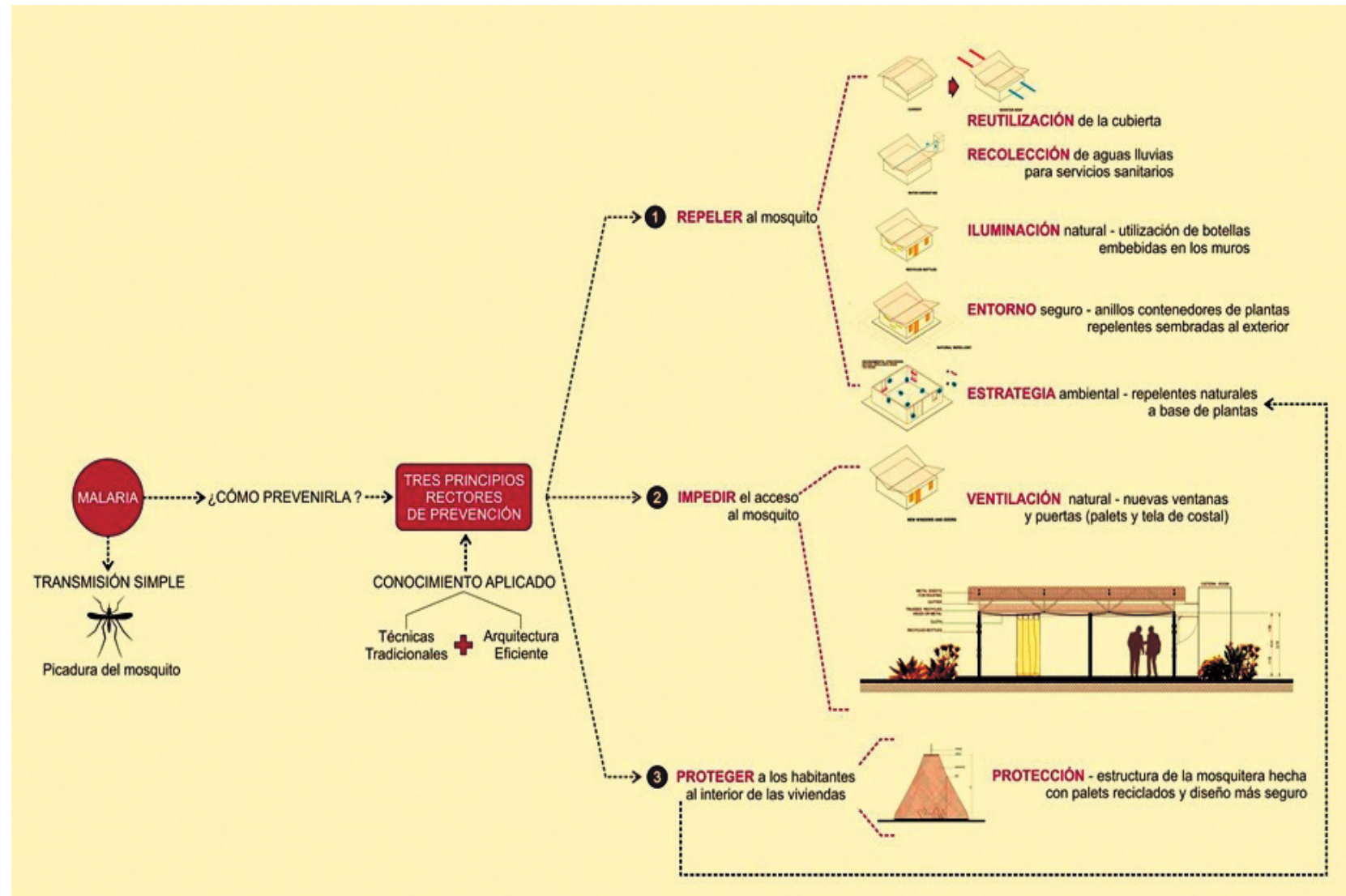


La arquitectura tradicional, incluso en condiciones de profunda escasez, no está exenta de aplicar técnicas que ayuden a prevenir la enfermedad. La propuesta se basa en aplicar técnicas tradicionales al contexto ya existente, ligar un patrimonio común a cualquier lugar y ser humano: el conocimiento, utilizar la naturaleza como aliada hacia la prevención. Dicho de otro modo, el concepto es tan profundo como simple a la vez: consiste en utilizar dichos saberes tradicionales junto con la capacidad de la comunidad para cambiar su realidad, su salud y eventualmente salvar la vida mediante la aplicación de medidas efectivas. La prevención de la enfermedad liga entonces la historia de la lucha local contra la enfermedad, optimizándola mediante la racionalización arquitectónica sin dejar de atender al contexto.

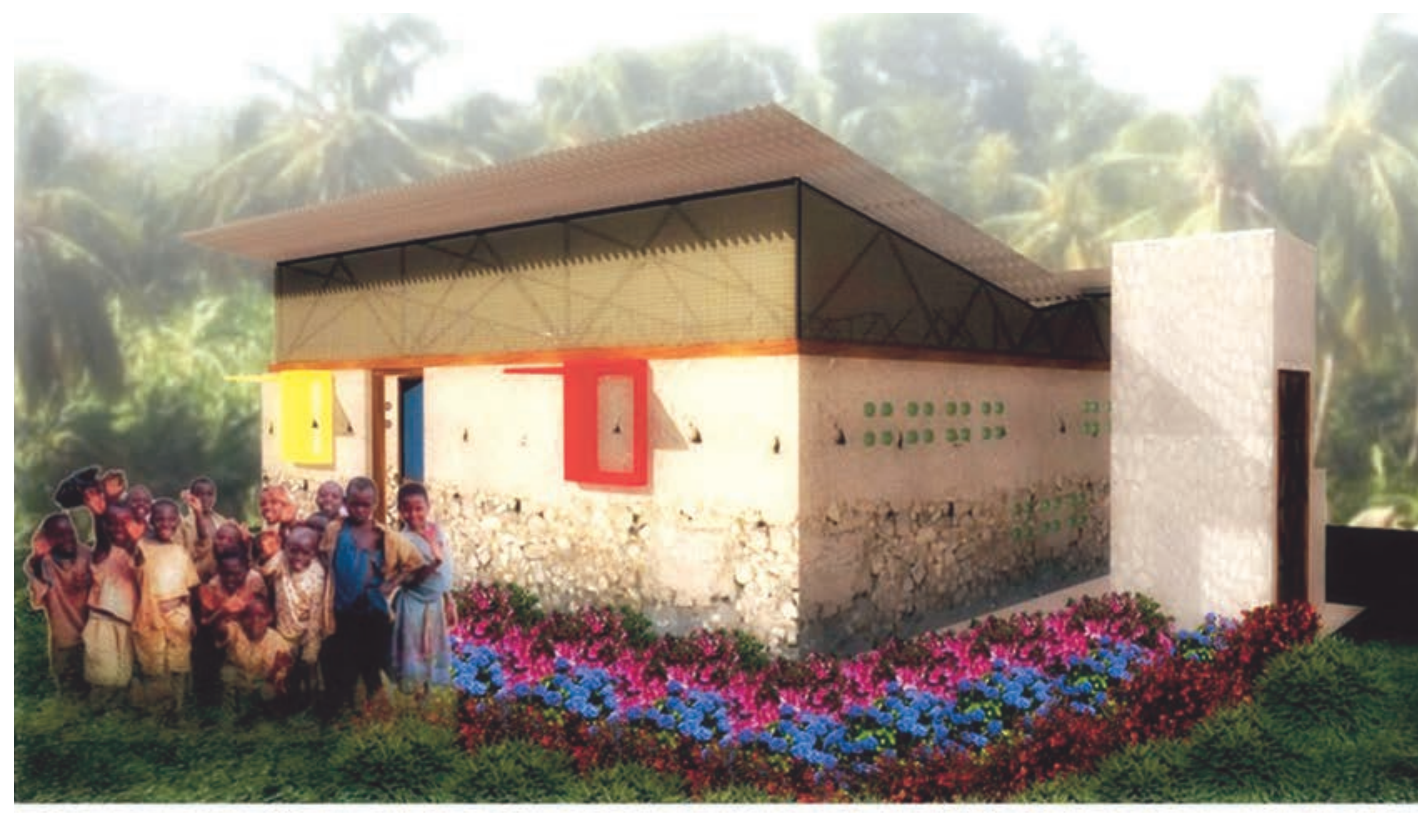

Figura 3. Imagen 3D de la vivienda propuesta. Fuente: Arquitecto Alejandro Ordóñez + Contrapunto Taller de Arquitectura. Suministrada por el autor.

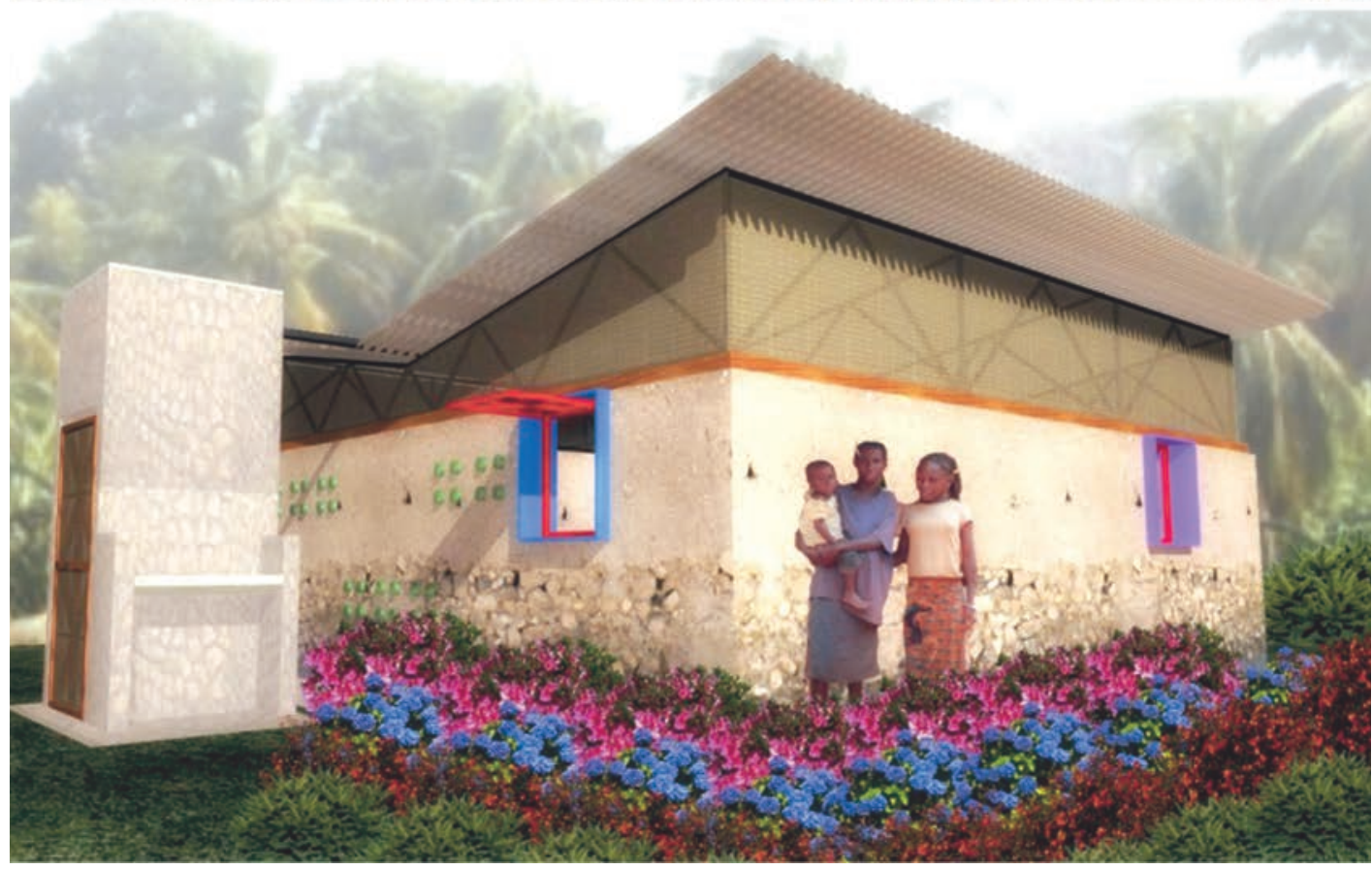




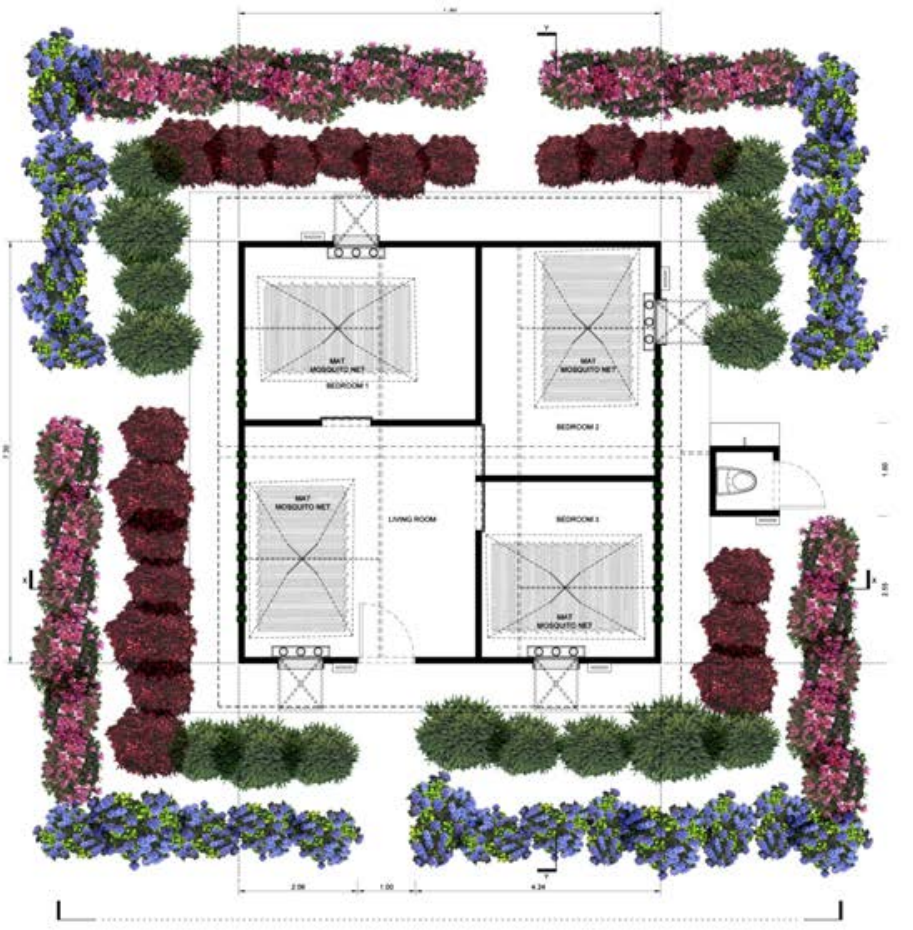

pount:
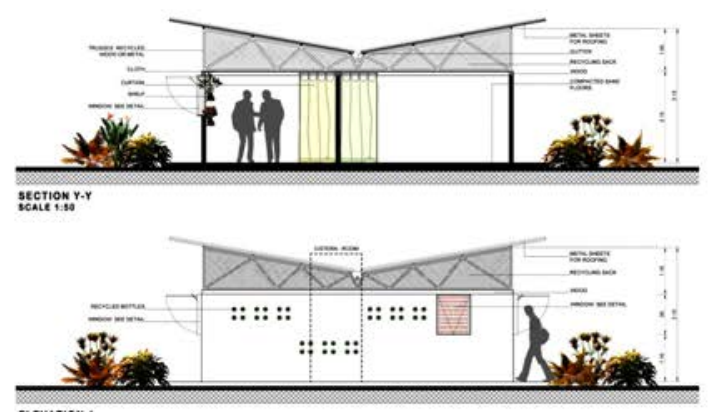

EegVarions

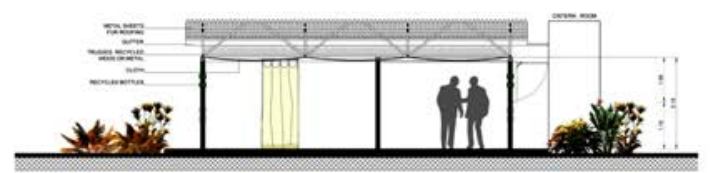

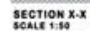

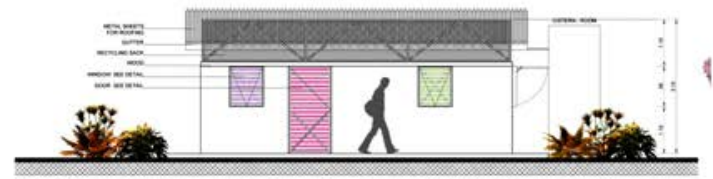

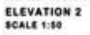

Figura 4. Fuente: Arquitecto Alejandro Ordóñez + Contrapunto Taller de Arquitectura. Suministrada por el autor.

Figura 5. Fuente: Arquitecto Alejandro Ordóñez + Contrapunto Taller de Arquitectura. Suministrada por el autor.
NATURAL PROTECTION

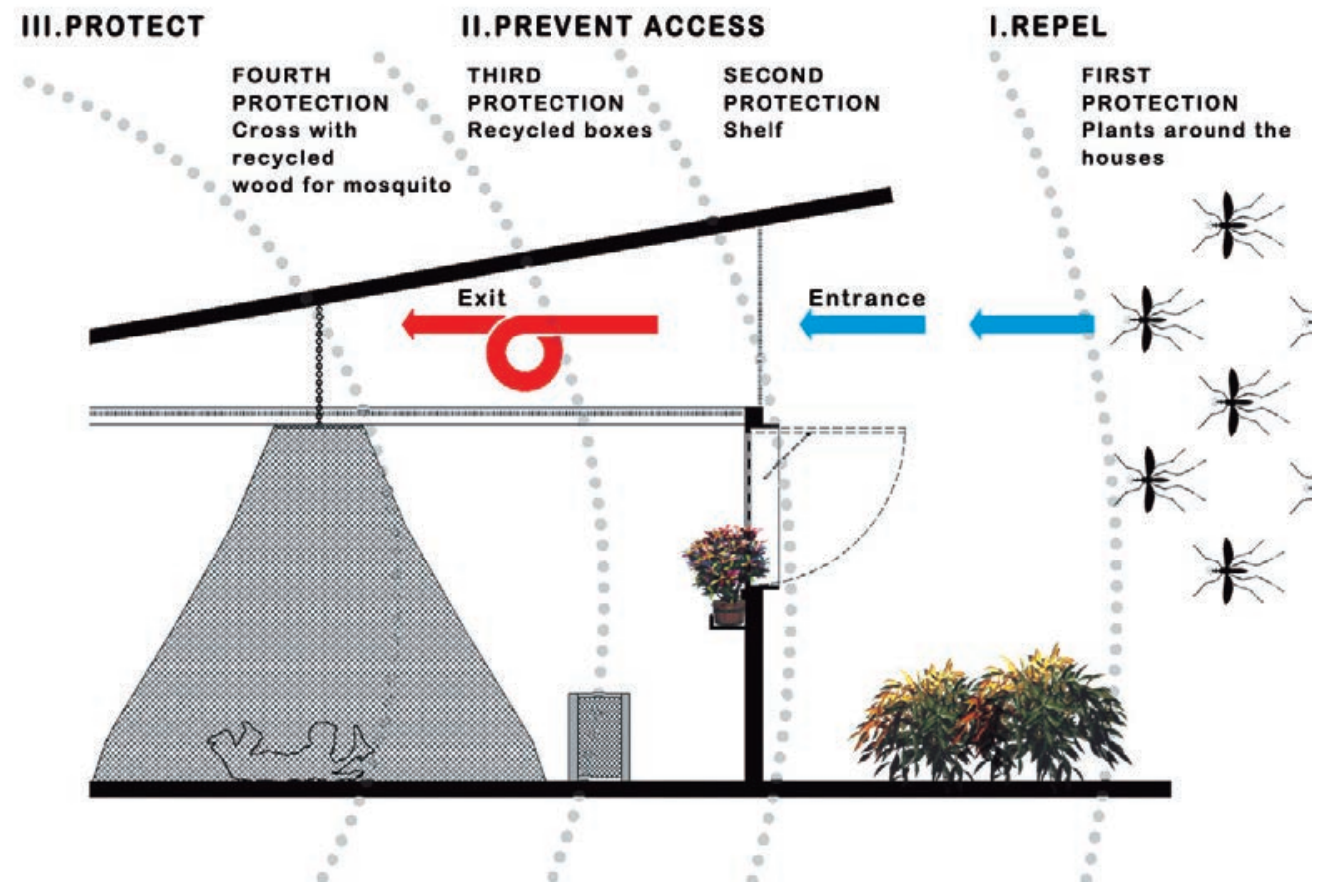




\section{CUTTING CONSTRUCTION}

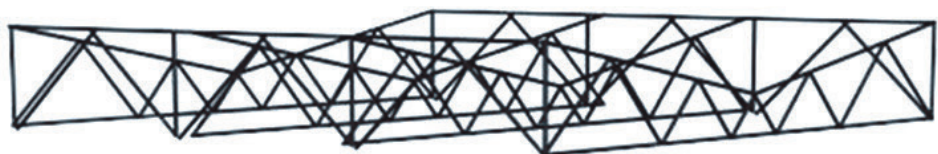

METAL SHEETS FOR

ROOFING

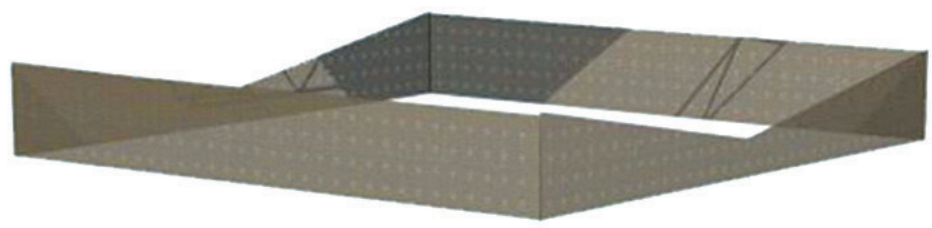

TRUSSES RECICLED

WOOD OR METAL

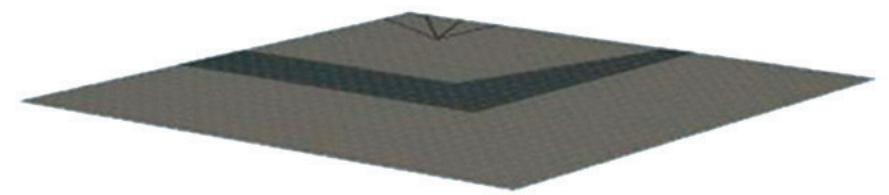

CEILING WEAVING

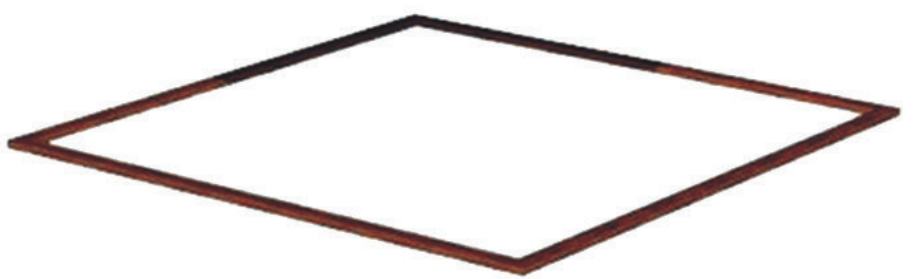

\section{RECYCLING SACK}

\section{WOOD FINISH}

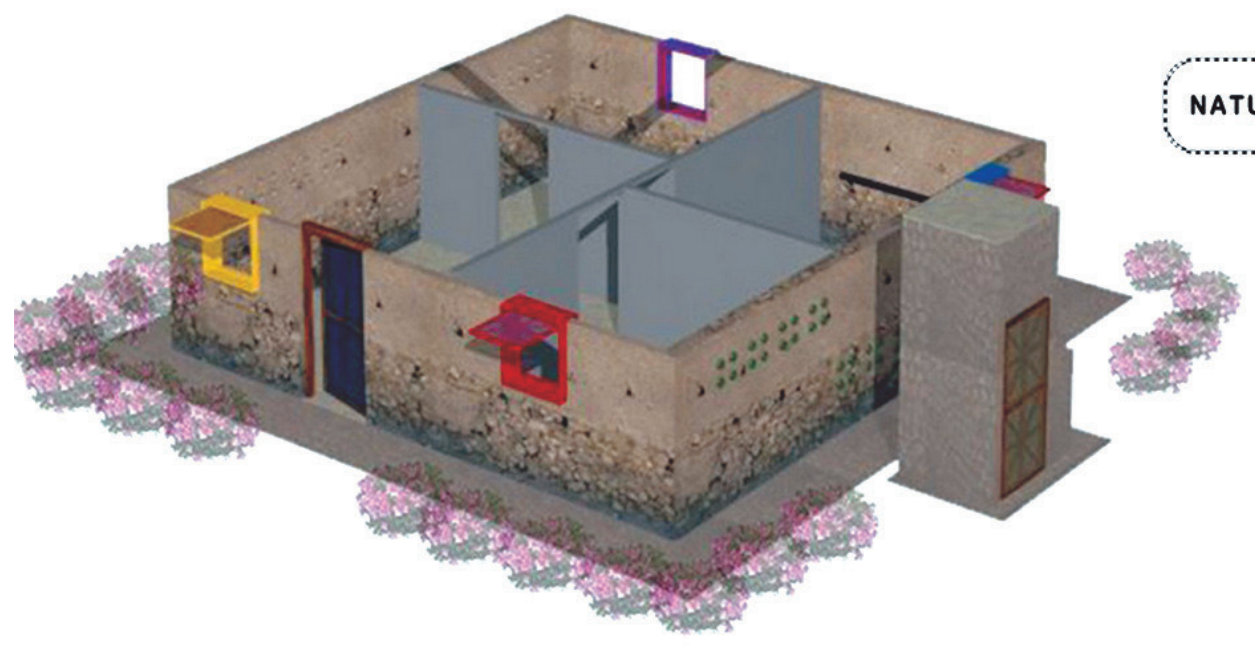

Figura 6. Fuente: Arquitecto Alejandro Ordóñez + Contrapunto Taller de Arquitectura. Suministrada por el autor. 


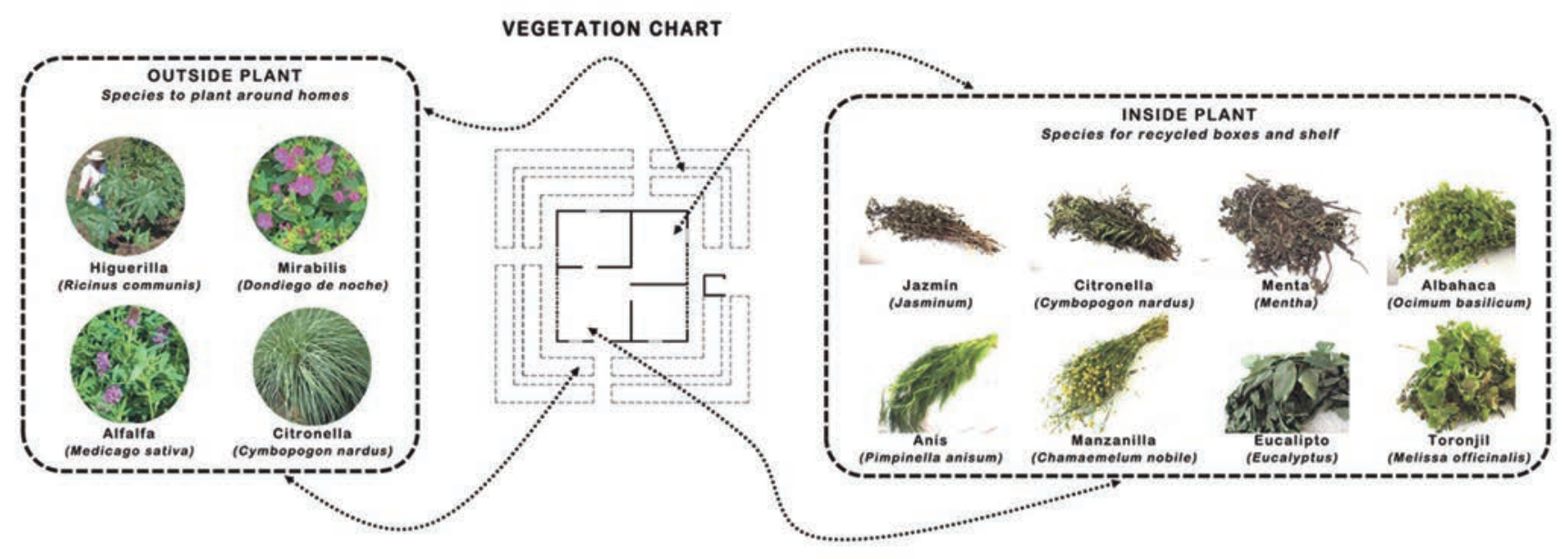

Figura 7. Fuente: Arquitecto Alejandro Ordóñez + Contrapunto Taller de Arquitectura. Suministrada por el autor.

La propuesta arquitectónica se presenta entonces mediante la implantación de estrategias, a saber:

a) Invertir los techos metálicos actuales, utilizar la estructura de madera existente complementándola con una estructura metálica y canalizar así el agua lluvia para que pueda ser recolectada en un tanque con el fin de generar servicios de aseo básicos, como, por ejemplo, la instalación de un sanitario (complementado esto con un pozo séptico a futuro). El tanque, construido en ladrillo común de la zona, deberá estar tapado, para evitar la proliferación del mosquito. De igual forma, voltear los techos producirá un flujo de ventilación natural constante. Esta ventilación al interior de la vivienda reducirá la humedad, y con ello, minimiza la posibilidad de permanencia del mosquito al interior. Esta acción está relacionada con el Principio I (repeler el mosquito en tanto se alteran las condiciones para su permanencia y proliferación).

b) Junto con la comunidad, tejer un cielo raso de tela para cada casa, que junto con el techo en forma de "V" producirá un efecto térmico al interior que filtra el acceso del mosquito. Este cielo raso, si bien puede ser de tela, puede también estar fabricado con sacos para empaque de café, producto de Camerún; todo esto atiende al Principio II. (Impedir el acceso del mosquito)

c) Al carecer de ventanas y puerta de acceso, los habitantes de las viviendas están más expuestos a la enfermedad. El proyecto propone fabricar ventanas en la obra con madera de palets o estibas, forradas con tela de costal pintadas según el deseo de cada familia, de acuerdo a los colores y estéticas locales. La puerta de acceso deberá estar conformada con madera. Es opcional que tenga la tela de costal, puesto que puede ser enteramente sólida para incrementar la seguridad de la vivienda. Principio II. (Impedir el acceso del mosquito)

d) Las malas condiciones de iluminación aumentan la humedad al interior de las viviendas y el mosquito trasmisor de la malaria siente atracción por estos lugares. Para mitigar este riesgo, se propone perforar dos de los muros exteriores que conforman la casa, a los que se insertarán botellas de vidrio recicladas que produzcan una incidencia positiva en las condiciones de iluminación natural al interior. Principio I. (Repeler al mosquito alterando las condiciones de humedad al dar luz a la vivienda)

e) Estrategias ambientales: Repelentes naturales a través de plantas que emiten olores, sembradas alrededor de las viviendas en forma de franjas protectoras. Estas franjas deben contener ejemplares de plantas como: Citronella (Cymbopogonnardus), Castor 
Oil Plant (Ricinus communis), Alfalfa (Medicago sativa) y Mirabilis Jalapa. Estas cuatro plantas, dispuestas alrededor de la casa generan una protección contra el mosquito a partir de sus olores. En una segunda instancia, se propone una repisa adosada a las ventanas, que al interior posibilite otra barrera medioambiental, esta vez con plantas en recipientes reciclados, ubicados tras la abertura de las ventanas. Estas plantas pueden ser de Piretro (Tanacetum cinerarii folium), ajo (Allium sativum) o anís (Pimpinella anisum), todas especies accesibles en Camerún. Por último, utilizar cajas recicladas de empaque de frutas, se propone un objeto móvil que contenga hierbas secas que transmitan olores. Este objeto móvil puede estar en las habitaciones, en la zona común, cerca de los niños cuando jueguen, colgadas en las circulaciones externas de la casa u otro sitio. Con esto se satisface el Principio I. (Repeler al mosquito mediante plantas) y el Principio III (Proteger a los habitantes al interior de las viviendas).

f) Pisos de tierra arcillosa compactada complementados con esteras africanas en las áreas principales.

g) Elaboración de una cruceta con madera reciclada de estiba, para colgar un mosquitero a la estructura de la cubierta. Esta cruz de madera permite que la malla cubra totalmente la cama o estera, elimine el contacto con la piel, por lo cual se aleja la posibilidad de que el mosquito pueda picar. Principio III (Proteger a los habitantes al interior de las viviendas).

Todas estas medidas, conjuntadas además con la construcción de un servicio sanitario fuera de la casa y el perfeccionamiento de las técnicas de tejidos autóctonos, se inscriben además en los objetivos que la OMS considera como fundamentales para la lucha contra la Malaria (por ejemplo: "define y difunde normas, criterios, políticas, estrategias técnicas y directrices basadas en datos científicos y promueve su adopción"). Visto desde esta perspectiva, la adopción de la propuesta está en plena armonía con los objetivos institucionales requeridos en cuanto a mitigación de riesgos de la salud derivados de la arquitectura, además de respetar las singularidades culturales de la región y aprovechar plenamente las herramientas naturales de flora, con lo que el contexto de precariedad africana se puede ver afectado positivamente. Valga decir que el proyecto se inscribe en Yaoundé, al interior de una comunidad de 24 familias.

Es necesario recordar además que se estima una reducción del $80 \%$ de contagio mediante la adopción de estas medidas.

El equipo de arquitectos proponentes del plan y ganadores del premio, visitó a inicios del 2013 la región en Camerún que iba a ser intervenida. De la mano de las organizaciones que respaldan el proyecto, se llevó a cabo un ciclo de reuniones con la comunidad para concertar la intervención arquitectónica, además de explicar sus alcances. Actualmente, se ultiman los detalles para el inicio de la construcción de las modificaciones a las viviendas, con lo que se espera que este proyecto de ayuda humanitaria se lleve a término y sirva de modelo bajo el auspicio de Archive Global Architecture for Health para combatir la Malaria y sus consecuencias en todo el continente africano.

La arquitectura, como cualquier actividad humana ligada a la cultura, debe ser la construcción colectiva y permanente de sentido. Dicho en otras palabras, el quehacer arquitectónico debe adquirir legitimidad ante los ojos de los hombres en tanto sirva para un fin mayor: la protección de la vida y la construcción de un mundo mejor. La construcción de un hogar no es otra cosa que la realización física de un objetivo: el intentar estar bien, la protección del propio ser y de los otros. Este entendimiento, que viene desde los primeros hogares hasta hoy, es el que ha dado sentido a las construcciones que dieron inicio a las ciudades $y$ al entendimiento real de lo que es la arquitectura.

M 91 REVISTA M VOL. 10 No.1. ENERO-JUNIO 2013 • FACULTAD DE ARQUITECTURA • UNIVERSIDAD SANTO TOMÁs COLOMBIA 


\section{GUÍA PARA AUTORES DE ARTícULOS}

Revista M publica artículos inéditos resultado de investigación que son sometidos a evaluación por pares especializados en los campos temáticos cubiertos por la revista. La evaluación se realiza "a ciegas" en doble sentido y no debe tomar más de dos (2) meses para su realización. El comité editorial se reserva el derecho de publicar o no los artículos que no cumplan con los criterios de publicación definidos por la Universidad Santo Tomás (Colombia). El autor debe garantizar que su artículo no ha sido publicado ni presentado a publicación en ningún medio diferente a Revista M.

La extensión de los artículos no debe ser mayor de 25 páginas en letra Arial, fuente No. 12 con interlineado a doble espacio.

Los artículos deben contener: Título, Resumen y Palabras clave en idioma español e inglés.

El autor debe especificar el nombre de la investigación de la cual su artículo se deriva.

El material del artículo debe ser enviado al Editor de la Revista a la cuenta revistaarqui@mail.ustabuca.edu.co en formato Word para el texto; las imágenes deben enviarse en archivos independientes en formato TIFF oJPG con resolución no menor a 300 DPI cada una. Se debe anexar en documento aparte el listado de imágenes con su respectivo pie de foto y la fuente u origen de las mismas; los derechos de reproducción de las imágenes serán gestionados directamente por los autores.

\section{Referencias bibliográficas}

A partir de 2013 Revista M utilizará la Norma definida por la Asociación Americana de Psicología (APA) para referencias bibliográficas. Ejemplos':

\section{Referencias:}

\section{Artículo de Revista}

Apellido, Inicial. (Año de publicación). Título del artículo. Título de la revista, volumen, página inicial-página final.

\section{Artículos en una revista científica exclusiva de Internet}

Apellido, Inicial. (Año de publicación, día, mes). Título del artículo. Título de la Revista, volumen. Recuperado el día de mes de año, de anotar URL.

I Tomado de: Guía Presentación trabajos estilo APA I Guías de apoyo - Formación de usuarios. Biblioteca USTA Bucaramanga, Colombia 


\section{Artículos de Internet basados en una fuente impresa}

Apellido, Inicial. (Año). Título [versión electrónica], Título de la revista, volumen, página inicial-página final.

\section{Copia electrónica de un artículo obtenido en una base de datos}

Autor, A.A. \& Autor, B.B. (año). Título del artículo. Título de la revista, volumen, (número), páginas. Recuperado el día de mes de año, de la base de datos tal.

\section{Libro completo:}

Apellido, Inicial. (Año). Título del libro. Lugar: Editorial. 


\section{GUIDE FOR AUTHORS OF ARTICLES}

Revista $M$ publishes original articles resulting from research that are subjected to review by specialized peers in thematic areas covered by the journal. The evaluation is done "blindly" in both directions and should not take more than two (2) months to be completed. The editorial board reserves the right to publish or not the items that do not meet the publication criteria defined by Santo Tomás University (Colombia ). The author must ensure that the article has not been published or submitted for publication in any other journal.

The length of articles should not exceed 25 pages in Arial font No. 12 double-spaced .

Items must contain: Title, Abstract and Keywords in Spanish and English .

The author must specify the name of the research from which the article derives.

The paper should be sent to the Editor of the journal to revistaarqui@mail.ustabuca. edu.co in Word format ; images must be sent as separate files in TIFF or JPG format with resolution no less than $300 \mathrm{DPI}$ each. The list of images must be attached in a separate file with their respective captions and source or origin; the rights to reproduce the images will be directly managed by the authors.

\section{References}

Revista $M$ uses the standard defined by the American Psychological Association (APA ) for references. Examples:

\section{Journal Article :}

Surname, Initial. (Year of publication). Title of article. Title of the journal, volume, initial page- final page.

\section{Articles in an exclusive scientific journal on the Internet:}

Surname, Initial. (Year of publication, day, month). Title of article. Title of the journal, volume, Retrieved on the day, month, year, URL scoring .

\section{Internet articles based on a printed source:}

Surname, Initial. (Year). Title [Electronic version ], Journal title, volume, initial page - final page. 


\section{Electronic copy of an article obtained from a database :}

Author, A. A. \& Author , B. B. (year). Title of article. Title of journal, volume, (number), pages. Retrieved month day, year, from database

\section{Full Book:}

Surname, Initial . (Year). Title of book. Location : Editorial .

\section{Revista M \\ ISSN 1692-5II4}

Facultad de Arquitectura

Universidad Santo Tomás, Colombia

Arq. Liliana Rueda Cáceres

Carrera 18 No 9-27. Bucaramanga, Colombia Teléfonos: 57 (7) 680080I. Ext.: 2500-224I

Mail: revistaarqui@mail.ustabuca.edu.co 